\title{
MOTIVASI SISWA PADA MATA PELAJARAN PPKN SELAMA PEMBELAJARAN DARING DI SEKOLAH DASAR
}

\author{
Oni Sahroni ${ }^{1}$, Rissa Nuryuniarti $^{2}$, Anggia Suci Pratiwi $^{3}$, Milah Nurkamilah $^{4}$ \\ ${ }^{1,2}$ Fakultas Kesehatan, Universitas Muhammadiyah Tasikmalaya \\ ${ }^{3,4}$ Fakultas Keguruan dan Ilmu Pendidikan, Universitas Muhammadiyah Tasikmalaya \\ 'onssahroni@gmail.com
}

\begin{abstract}
Online learning is learning that must be carried out by teachers during a pandemic like now. The purpose of this study is to find out whether there are differences in motivation before and after implementing online learning in PPKn subjects at SDN Gunung Lipung1 Kota Tasikmalaya for the 2019-2020 school year. This research method uses quantitative techniques with quasi experimental techniques and the design is one group pre test and post test design. The sample of this study were students of class V and VI SDN Gunung Lipung1 Kota Tasikmalaya. The research instruments used questionnaires and interviews. The results showed that online learning carried out by PPKn teachers at SDN Gunung Lipung1 Kota Tasikmalaya was able to increase student motivation. The results of the hypothesis test show that there are differences in motivation before and after the implementation of online learning in PPKn subjects at SDN Gunung Lipung1 Kota Tasikmalaya for the 2019-2020 school year.
\end{abstract}

Keywords: student motivation; online learning

\begin{abstract}
Abstrak
Pembelajaran daring merupakan pembelajaran yang harus dilaksanakan oleh guru saat terjadi pandemi seperti sekarang ini. Tujuan dari penelitian ini adalah untuk mengetahi apakah terdapat perbedaan motivasi sebelum dan sesudah pelaksanaan pembelajaran daring pada mata pelajaran PPKn di SDN Gunung Lipung1 Kota Tasikmalaya tahun pelajaran 2019-2020. Metode penelitian ini menggunakan teknik kuantitatif dengan teknik quasi eksperimental dan designya adalah one group pre test and post test design. Sampel dari penelitian ini adalah siswa kelas V dan VI SDN Gunung Lipung1 Kota Tasikmalaya. Instrumen penelitian menggunakan angket dan wawancara. Hasil penelitian menunjukan bahwa pembelajaran daring yang dilaksanakan oleh guru PPKn di SDN Gunung Lipung1 Kota Tasikmalaya mampu meningkatkan motivasi siswa. Hasil uji hipotesis menunjukan bahwa terdapat perbedaan motivasi sebelum dan sesudah pelaksanaan pembelajaran daring pada mata pelajaran PPKn di SDN Gunung Lipung1 Kota Tasikmalaya tahun pelajaran 2019-2020

Kata Kunci: motivasi siswa; pembelajaran daring
\end{abstract}

\begin{tabular}{llll}
\hline Received & $: 2020-08-22$ & Approved & $: 2020-12-21$ \\
Reviesed & $: 2020-11-09$ & Published & $: 2021-01-31$
\end{tabular}

(C) (D) (2) Jurnal Cakrawala Pendas is licensed under a Creative Commons Attribution-

ShareAlike 4.0 International License.

\section{Pendahuluan}

Motivasi merupakan bagian terpenting dalam siswa yang dapat mempengaruhi keberhasilan siswa dalam belajar. Motivasi bermakna motif atau dorongan dari seseorang untuk melakukan sesuatu (Ismiyati, 2015) (Yatim, 2016). Motivasi menjadi penting karena akan menjadi penguat siswa dalam melaksanakan pembelajaran. Perlu disadari atau tidak bahwa siswa yang memiliki motivasi yang tinggi sejalan dengan kemampuan yang dimilikinya (Kholisna \& Widayati, 2018). Oleh karena itu penting kiranya guru apapun untuk dapat membantu siswa dalam meningkatkan motivasinya. Mata pelajaran Pendidikan Pancasila di dalam masa pandemi perlu mendapatkan perhatian khusus. Hal ini dikarenakan motivasi siswa harus dapat ditingkatkan meskipun dalam masa pandemi seperti ini. Motivasi menjadi 
penting karena riset terdahulu memberikan kontribusi terhadap hasil belajar seseorang. Motivasi pada dasarnya terbagi menjadi dua ada motivasi intrinsic dan motivasi ekstrensik (Lin et al., 2017). Baik motivasi intrinsic maupun ekstrensik keduanya akan saling melengkapi satu sama lainnya (Block et al., 2013). Motivasi belajar diperlukan seseornag agar memiliki keyakinan yang melekat dan mendorong perilaku belajar sehingga siswa mampu meningkatkan hasil belajarnya (Shabani, 2012).

Motivasi intrinsik yang berupa dorongan dalam diri seseorang perlu kiranya menjadi perhatian guru dan orang tua di rumah (Hamm et al., 2019; Kim \& Frick, 2011; Yustina et al., 2020). Hal ini didasarkan bahwa siswa lebih banyak menghabiskan waktunya di dalam lingkungan keluarga. Banyak yang berpendapat bahwa motivasi intrinsik lebih banyak pengaruhnya terhadapi hasil belajar seseorang, hal ini sesuai dengan pendapat intrinsic motivation might be more autonomous and persistent with high value, but environmental factors could also influence motivation that incentives and external support were necessary (Im et al., 2011). Berdasarkan pendapat tersebut meskipun motivasi internal lebih menjadi bagian utama dalam mendorong hasil belajar seseorang tetapi motivasi eksternal bisa mendorong untuk terjadinya motivasi internal. Ambil contoh kasus, seorang siswa mendapatkan lingkungan belajar yang baik di sekolahnya. Teman yang lain memiliki semangat yang tinggi untuk berprestasi di kelasnya. Lama lama kelamaan siswa tersebut akan timbul motivasi internalnya dikarenakan juga memiliki keinginan menjadi yang terbaik di kelasnya. Itulah contoh kasus bahwa motivasi eksternal dapat mendorong siswa untuk memiliki motivasi internal yang baik.

Beberapa kasus memperlihatkan bahwa siswa lebih tertantang untuk menyelesaikan tugasnya secara sendiri (motivasi intrinsik) tetapi dalam hal tertentu siswa memerlukan bantuan baik dari siswa ataupun guru untuk menyelesaikan masalah masalah tertentu (Chou et al., 2012). Maksud dari pernyataan tersebut adalah bahwa siswa dalam hal kasus tertentu katakanlah soal yang membutuhkan penalaran yang lebih dituntut untuk mampu mememcahkan masalah tersebut tetapi pada kondisi siswa mengalami kebuntuan untuk memecahkan soal tersebut maka siswa tersebut membuthkan bantuan dari guru atau teman yang lainnya. Inilah menunjukan bahwa motivasi eksternal memiliki pengaruh yang tidak kalah penting dibandingkan dengan motivasi internal. Oleh karena itu kedua motivasi ini perlu dikembangkan baik di dalam lingkungan sekolah maupun di luar lingkungan sekolah, karena motivasi banyak memberikan pengaruh terhadap prestasi siswa di sekolah (Cai \& Zhu, 2012; Keskin \& Yurdugül, 2019; Stark, 2019; Zhang et al., 2019).

Pendidikan Kewarganegaraan (PPKn) adalah pendidikan yang melatih kemapuan agar dapat berfikir kritis dan rasional serta kreatif seorang warga negara demi menjadi warga negara yang baik. Baik (Hapsari \& Dwi Wicaksono, 2018). Hal ini juga senada bahwa PPKn bertujuan untuk menjadi warga Negara yang baik sesuai dengan hukum dan UUD 1945 (Alfansyur \& Mariyani, 2019). Maksud dari menjadi manusia yang baik adalah manusia yang taat dan sadar hokum dan mampu mengamalkan nilai nilai luhur bangsa Indonesia dan siap diberikan sanksi jika melanggar ketentuan hokum yang berlaku. Selain itu mata pelajara PPKn diberikan agar siswa tahu dan paham anatara hak dan kewajibannya sebagai warga Negara yang diatur menurut Undang Undang (Tuken, 2016), Selain itu bahwa mata pelajaran PPKn juga didik agar memilik sikap kritis, kreatif dan rasional (Rendra, N. T. dan Widiastini, $\mathrm{N} \mathrm{W}$, 2017). Perlu kiranya guru mengembangkan motivasi siswa baik intrinsik maupun ekstrinsik agar mampu mendorong hasil belajar pada mata pelajaran PPKn. Penelitian ini lebih berfokus kepada pengukuran motivasi belajar siswa sebelum dan sesudah pelaksanaan pembelajaran daring yang dilaksanakan oleh guru PPKn di SDN Gunung lipung 1. Melalui 
penelitian ini diharapkan akan mampu melihat motivasi belajar selama pembelajaran daring. Pembelajaran daring dalam penelitian ini lebih difokuskan kepada penilaian motivasi siswa selama pembelajaran daring berlangsung

\section{Metode Penelitian}

Metode penelitian ini menggunakan teknik kuantitatif dengan teknik quasi eksperimental dan designya adalah one group pre test and post test design. Penelitian ini dilaksanakan di kelas V dan VI SDN Gunung Lipung 1 Tasikmalaya, yang beralamat di jalan Ampera Barat, Panglayungan, Cipedes Kota Tasikmalaya Tahun Pelajaran 2019-2020. Alasan mengambil kelas V dan kelas VI karena rata-rata sudah mengenai pengisian angket di dalam google form. Jumlah respondel dalam sampel terdiri dari V sebanyak 38 orang dan kelas VI sebanyak 39 orang, sehingga total keseluruhan adalah sebanyak 77 orang.

Instrumen penelitian yang digunakan adalah angket motivasi yang didesain khsusu menggunakan goggle form, sehingga siswa tinggal mengisi angket tersebut menggunakan smartphonenya. Indikator motivasi belajar mengambil dua pendapat yaitu motivasi intrinsik dan motivasi ekstrinsik. Motivasi dari dalam dibagi ke dalam sub kategori dorongan dan kebutuhan dalam belajar, kemampuan dalam belajar dan kegiatan yang menarik dalam belajar. Sedangkan motivasi ekstrinsik memiliki sub bagian adanya penghargaan dalam belajar (Hapsari \& Dwi Wicaksono, 2018).

Analisis data dalam penelitian ini dimulai dari analisis deksriptif yaitu mencari mean, median, modus serta standar deviasi. Selanjutnya dilakukan uji normalitas untuk mengetahui apakah sebaran data normal atau tidak, jika sebaran data normal maka dilanjutkan dengan uji paramateri yaitu uji paired sample $t$ test dan jika tidak normal maka dilanjutkan kepada uji Wilcoxon. Semua instrument yang digunakan sudah dilakukan terlebih dahulu cek validitas dan reliabilitasnya, sehingga layak untuk digunakan. Jumlah seluruh pertanyaan sebanyak 20 pernyataan yang masing masing sub kategori terdiri dari 5 pernyataan

\section{Hasil dan Pembahasan}

Hasil penelitian ini difokuskan pada dua hal yang menjadi dasar dari tujuan penelitian ini yaitu motivasi belajar siswa dan perbandingan motivasi belajar siswa kelas V dan VI SDN Gunung Lipung 1 Kota Tasikmalaya sebelum dan sesudah pembelajaran daring di laksanakan. Adapun penjelasannya sebagai berikut:

3.1 Pelaksanaan Pembelajaran pada Mata Pelajaran PPKn di SDN Gunung Lipung 1 Tahun Pelajaran 2019-2020

Pelaksanaan pembelajaran di SDN Gunung Lipung 1 mulai Maret dilakukan secara daring mengingat anjuran pemerintah untuk mencegah penyebaran Covid19. Beberapa langkah antisipasi dilakukan agar pembelajaran dapat terlaksana dengan baik meskipun disituasi sulit karena tidak semua siswa memiliki perangkat yang memadai untuk melaksanakan pembelajaran daring. Kami selaku tim peneliti melakukan wawancara dengan guru kelas., ada beberapa informasi yang bisa kami dapatkan setelah melaksanakan wawancara dengan guru kelas. Hasil wawancaranya adalah seabgai berikut:

Peneliti mendapatkan informasi mengenai kesipan guru dalam mengajar kemudian guru menyatakan pembelajaran daring sudah dipersiapkan oleh sekolah dalam mengantisipasi terjadi pandemi ini, kami menggunakan beberapa patform dan membebaskan guru untuk melaksanakan melalui platform yang sudah ada. Kemudian pembahasan dilanjutkan kepada platform yang digunakan dalam pembelajaran daring. Guru memberikan pernyataan menjawab bahwa kami diberikan kebebasan oleh sekolah untuk menggunakan platform 
apapun dalam pembelajaran daring yang penting bisa diikuti oleh siswa, dan siswa memahami dengan baik materi yang disampaikan oleh guru meskipun dengan sistem daring. Khusus pada mata pelajaran PPKn guru menyampaikan dengan beberapa cara mulai dari Google Class Room, Whatsup Gorup, terkadang juga kuis menggunakan Kahoot. Semua dilakukan agar pembelajaran berjalan dengan efektif. Alasan mengambil pembelajarna dengan menggunakan Whtasup adalah karena ada sebagian kelompok siswa yang membeli internet hanya untuk paket chat saja sehingga pada kelompok ini jika melaksanakan pembelajaran dengan menggunakan Whatsup masih bisa mengikutinya. Untuk absen dan tugas digunakan google form. Hal ini dilakukan untuk mempermudah merekap sehingga kami guru tidak perlu merekap lagi. Semua proses pembelajaran dilaksanakan secara daring dengan ketentuan bahwa semua siswa berhak mendapatkan pembelajaran dan guru berkewajiban untuk menyampaikan pembelajaran. Setelah dari guru kelas kami mencoba menghubungi kepala SDN Gunung Lipung 1, beliau mengintruksikan kepada semua guru untuk memanfaatkan semua fasilitas yang ada termasuk jika tidak memiliki perangkat gurunya bisa datang ke sekolah dengan menggunakan protocol kesehatan sesuai dengan anjuran pemerintah.

\section{Motivasi Belajar Siswa Sebelum dan Sesudah Pelaksanaan Pembelajaran Daring}

Penelitian ini disamping melihat proses pembelajaran daring yang dilakukan oleh guru kelas dalam mata pelajaran PPKn di SDN Gunung Lipung 1 Kota Tasikmalaya, penelitian ini juga berfokus kepada motivasi siswa sebelum dan sesudah pembelajaran daring yang dilaksanakan di SDN Gunung Lipung 1 Kota Tasikmalaya. Angket yang terdiri dari 20 pernyataan sudah di susun berdasarkan indikatornya. Semua siswa yang menjadi sampel penelitian mengisi pernyataan menggunakan google form yang telah disediakan oleh peneliti. Hasil dari motivasi siswa sebelum pembelajaran daring adalah sebagai berikut:

Tabel 1. Deskripsi Data Motivasi Sebelum Pembelajaran Daring

\begin{tabular}{lr}
\hline \multicolumn{1}{c}{ Motivasi_Sebelum } \\
\hline Valid N & 79 \\
Range & 45.00 \\
Minimum & 43.00 \\
Maximum & 88.00 \\
Sum & 4642.00 \\
Mean & 58.7595 \\
Std. Deviation & 9.85564 \\
Variance & 97.134 \\
\hline
\end{tabular}

Tabel 1 memperlihatkan bahwa nilai rata-rata motivasi sebelum pembelajaran daring adalah 58,7595, jika kita gunakan kategori motivasi belajar maka nilai rata-rata tersebut termasuk pada kategori cukup. Hasil tersebut memberikan gambaran bahwa motivasi belajar siswa berada pada kategori cukup yaitu perlu adanya peningkatan motivasi belajar setelah pelaksanaan pembelajaran daring dilaksanakan. Kemudian hasil motivasi sesudah pembelajaran daring dapat ditampilkan sebagai berikut: 
Tabel 2. Deskripsi Data Motivasi Sesudah Pembelajaran Daring

\begin{tabular}{lr}
\hline \multicolumn{2}{c}{ Motivasi_Sesudah } \\
\hline Valid N & 79 \\
Range & 45.00 \\
Minimum & 53.00 \\
Maximum & 98.00 \\
Sum & 5800.00 \\
Mean & 73.4177 \\
Std. Deviation & 10.57405 \\
Variance & 111.810 \\
\hline
\end{tabular}

Berdasarkan data tersebut terlihat bahwa skor maksimum motivasi siswa berada pada nilai 98 dengan skor rata-rata 73,4177. Berdasarkan skor rata-rata tersebut maka kategori motivasi sesudah pembelajaran daring berada pada kategori baik. Untuk melihat perbedaan yang dapat divisualisasikan melalui diagram batang perbandingan motivasi sebeum dan sesudah melaksanakan pembelajaran daring

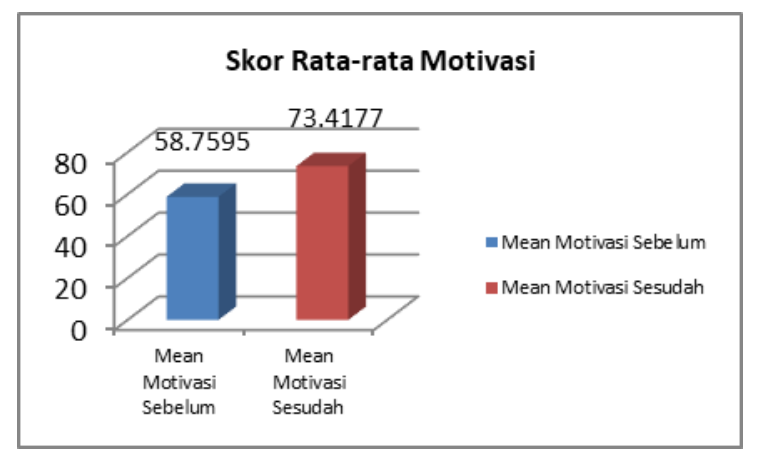

Gambar 1. Diagram Batang Perbandingan Motivasi Sebelum dan Sesudah Pembelajaran Daring di SDN Gunung Lipung 1 Kota Tasikmalaya

Berdasarkan skor rata-rata tersebut terlihat perbedaan yang cukup mencolok yaitu warna merah sebagai motivasi sesudah pembelajaran daring sebesar 73,4177 dan warna biru motivasi sebelum pembelajaran daring yaitu sebesar 58,7595. Diagram batang tersebut memberikan gambaran bahwa guru telah berhasil melaksanakan pembelajaran daring yang mampu meningkatkan motivasi siswa dalam belajar pada mata pelajaran PPKn, namun demikian perlu diuji apakah perbedaan tersebut signifikan secara statistik.

Kriteria pengujian terima Ho jika nilai signifikansi $>0,05$. Uji normalitas menggunakan uji Shapiro wilk, dengan hasil sebagai berikut:

Tabel 3. Hasil Uji Normalitas

\begin{tabular}{cc}
\hline Uji Normalitas & Nilai Signifikansi \\
\hline Motivasi Sebelum & 0,000 \\
Motivasi Sesudah & 0,002 \\
\hline
\end{tabular}

Berdasarkan tabel tersebut bahwa nilai signifikansi baik motivasi sebelum maupun sesudah berada $<0,05$ dengan demikian dapat disimpulkan bahwa sebaran data tidak normal. Berdasarkan kedua gambar tersebut maka baik histogram motivasi sebelum dan histogram motivasis sesudah memiliki kurva yang tidak menyerupai kurva normalitas yaitu kurva yang memiliki kemiripan lonceng. Oleh karena distribusi data tidak normal, maka uji hipotesis 
dilanjutkan dengan uji non paramterik, yaitu menggunakan uji Wilcoxon, pasangan hipotesis yang diuji adalah sebagai berikut:

Ho: Tidak terdapat perbedaan motivasi sebelum dan sesudah pelaksanaan pembelajaran daring pada mata pelajaran PPKn di SDN Gunung Lipung 1 Kota Tasikmalaya

Ho: Terdapat perbedaan motivasi sebelum dan sesudah pelaksanaan pembelajaran daring pada mata pelajaran PPKn di SDN Gunung Lipung 1 Kota Tasikmalaya

Kriteria pengujian tolak Ho jika nilai signifikansi $<0,05$. Hasil dari uji Wilcoxon adalah sebagai berikut:

Tabel 5. Hasil Uji Wilcoxon

\begin{tabular}{lc}
\hline & Nilai Signifikansi \\
\hline Uji Wilcoxon & 0,000 \\
Kesimpulan & Ho ditolak \\
\hline
\end{tabular}

Berdasarkan Tabel tersebut terlihat bahwa kesimpulannya Ho ditolak sehingga dapat disimpulkan bahwa terdapat perbedaan motivasi sebelum dan sesudah pelaksanaan pembelajaran daring pada mata pelajaran PPKn di SDN Gunung Lipung 1 Kota Tasikmalaya Tahun Pelajaran 2019-2020.

Beberapa hal yang menjadi catatan dari hasil penelitian ini adalah bahwa guru telah cukup berhasil dalam melaksanakan pembelajaran yang mampu meningkatkan motivasi siswa dalam belajar. Beberapa siswa kami wawancarai dan dapat di simpulkan bahwa siswa merasa termotivasi dengan tugas yang diberikan oleh guru, dan pemberian penghargaan oleh guru kepada siswa sehingga motivasinya juga ikut meningkat. Selain itu siswa juga melihat bahwa tugas yang diberikan oleh guru terstruktur dan dapat dilaksanakan oleh siswa dengan kondisi pandemi seperti saat ini. Hasil ini menunjukan bahwa guru telah berhasil melaksanakan pembelajaran daring pada mata pelajaran PPKn di SDN Gunung Lipung 1 Kota Tasikmalaya, Pembelajaran daring yang dikemas dengan menarik akan mampu memberikan motivasi kepada siswa dalam belajar, perlu menjadi perhatian bagi guru agar motivasi menjadi salah satu faktor psikologi yang penting untuk diperhatikan agar prestasi dan kemampuan siswa dapat ditingkatkan (Carter Jr et al., 2020; Law et al., 2019; Susilawati \& Supriyatno, 2020).

\section{Kesimpulan}

Berdasarkan pengolahan dan analisis data data disimpulkan bahwa pembelajaran daring yang dilaksanakan oleh guru PPKn di SDN Gunung Lipung 1 Kota Tasikmalaya mampu meningkatkan motivasi siswa. Hasil uji hipotesis menunjukan bahwa terdapat perbedaan motivasi sebelum dan sesudah pelaksanaan pembelajaran daring pada mata pelajaran PPKn di SDN Gunung Lipung 1 Kota Tasikmalaya tahun pelajaran 2019-2020.

\section{Daftar Pustaka}

Alfansyur, A., \& Mariyani. (2019). Pemanfaatan Media Berbasis Ict "Kahoot " Dalam Pembelajaran PPKN Untuk Meningkatkan Motivasi. Bhineka Tunggal Ika: Kajian Dan Ptaktik PKn, 6(2), 208-216. https://doi.org/10.36706/jbti.v6i2.10118

Block, L., Jesness, R., \& Schools, M. P. (2013). One-to-One Learning with iPads: Planning \& Evaluation of Teacher Professional Development. College of Education, Leadership \& Counseling. University of ST. Thomas Minnesota.

Cai, S., \& Zhu, W. (2012). The impact of an online learning community project on university Chinese as a foreign language students' motivation. Foreign Language Annals, 45(3), 307329. 
Carter Jr, R. A., Rice, M., Yang, S., \& Jackson, H. A. (2020). Self-regulated learning in online learning environments: strategies for remote learning. Information and Learning Sciences.

Chou, C. C., Block, L., \& Jesness, R. (2012). A case study of mobile learning pilot project in K-12 schools. Journal of Educational Technology Development and Exchange (JETDE), 5(2), 3.

Hamm, J. M., Perry, R. P., Chipperfield, J. G., Parker, P. C., \& Heckhausen, J. (2019). A motivation treatment to enhance goal engagement in online learning environments: Assisting failure-prone college students with low optimism. Motivation Science, 5(2), 116.

Hapsari, D., \& Dwi Wicaksono, V. (2018). PENGARUH PENGGUNAAN METODE PERMAINAN BINGO TERHADAP MOTIVASI DAN PEMAHAMAN MATERI PPKn KELAS IV SDN SUMOKEMBANGSRI SIDOARJO. Jurnal Penelitian Pendidikan Guru Sekolah Dasar, 6(7), 1-11.

Im, I., Hong, S., \& Kang, M. S. (2011). An international comparison of technology adoption: Testing the UTAUT model. Information \& Management, 48(1), 1-8.

Ismiyati, I. (2015). PENINGKATAN PRESTASI DAN MOTIVASI BELAJAR PPKn SISWA KELAS VIII A SMP NEGERI 2 GEDANGSARI - GUNUNGKIDUL MELALUI PEMBELAJARAN GROUP INVESTIGATION. Scholaria: Jurnal $\begin{array}{llll}\text { Pendidikan Dan } & \text { Kebudayaan, }\end{array}$ https://doi.org/10.24246/j.scholaria.2015.v5.i1.p39-56

Keskin, S., \& Yurdugül, H. (2019). Factors affecting students' preferences for online and blended learning: Motivational vs. cognitive. European Journal of Open, Distance and ELearning, 22(2).

Kholisna, \& Widayati, S. (2018). PENGARUH MOTIVASI DAN KEDISIPLINAN TERHADAP PRESTASI BELAJAR PPKN SISWA KELAS VIII SMP MUHAMMADIYAH 13 WONOSEGORO. Jurnal Waspada UNDARIS, 4(2), 1-11.

Kim, K.-J., \& Frick, T. W. (2011). Changes in student motivation during online learning. Journal of Educational Computing Research, 44(1), 1-23.

Law, K. M. Y., Geng, S., \& Li, T. (2019). Student enrollment, motivation and learning performance in a blended learning environment: The mediating effects of social, teaching, and cognitive presence. Computers \& Education, 136, 1-12.

Lin, M. H., Chen, H. C., \& Liu, K. S. (2017). A study of the effects of digital learning on learning motivation and learning outcome. Eurasia Journal of Mathematics, Science and Technology Education, 13(7), 3553-3564. https://doi.org/10.12973/eurasia.2017.00744a

Rendra, N. T. dan Widiastini, N W, E. (2017). Pembelajaran PPKn SD. Fakultas Ilmu Pendidikan Undiksha.

Shabani, K. (2012). Dynamic assessment of L2 learners' reading comprehension processes: A Vygotskian perspective. Procedia-Social and Behavioral Sciences, 32, 321-328.

Stark, E. (2019). Examining the Role of Motivation and Learning Strategies in Student Success in Online versus Face-to-Face Courses. Online Learning, 23(3), 234-251.

Susilawati, S., \& Supriyatno, T. (2020). Online learning through WhatsApp group in improving learning motivation in the era and post pandemic COVID-19. Jurnal Pendidikan: Teori, Penelitian, Dan Pengembangan, 5(6), 852-859.

Tuken, R. (2016). Peningkatan Hasil Belajar Siswa pada Mata Pelajaran Pkn Melalui Pembelajaran Kooperatif tipe Role Playing di Kelas VI SDN IV Kota Parepare. Publikasi Pendidikan, 6(2).

Yatim, D. (2016). Penggunaan Penguatan Dalam Pembelajaran Bidang Studi Ppkn Di Kelas Ix Smpn 10 Tenggarong. CENDEKIA: Journal of Education and Teaching, 10(1), 79. https://doi.org/10.30957/cendekia.v10i1.84

Yustina, Y., Halim, L., \& Mahadi, I. (2020). The Effect of'Fish Diversity'Book in Kampar District on the Learning Motivation and Obstacles of Kampar High School Students through Online Learning during the COVID-19 Period. Journal of Innovation in Educational and Cultural Research, 1(1), 7-14.

Zhang, Q., Bonafini, F. C., Lockee, B. B., Jablokow, K. W., \& Hu, X. (2019). Exploring demographics and students' motivation as predictors of completion of a massive open online course. International Review of Research in Open and Distributed Learning, 20(2). 